\title{
Development of future teachers readiness for academic mobility
}

\author{
Vladimir Borisenkov ${ }^{1, *}$, Olga Gukalenko ${ }^{2}$, Vyacheslav Kazarenkov ${ }^{3}$, Tatiana Kazarenkova ${ }^{4}$ \\ and Marina Karnialovich ${ }^{5}$ \\ ${ }^{1}$ Lomonosov Moscow State University, Leninskie Gory, Moscow, 119991, Russian Federation \\ ${ }^{2}$ Russian Academy of Education, Pogodinskaya str. 8, Moscow, 119121, Russian Federation \\ ${ }^{3}$ RUDN Unversity. Miklukho-Maklaya str. 6, Moscow, 611798, Russian Federation \\ ${ }^{4}$ International Research Centre "Socium 2035", Pyatnitskaya str. 37, Moscow, 119017, Russian \\ Federation \\ ${ }^{5}$ Yanka Kupala State University of Grodno. Ozheshko str. 22, Grodno, Belarus
}

\begin{abstract}
The article deals with problematic issues of international student mobility of students as a means of professional and personal selfdevelopment of future teachers. The aim of the research is to determine theoretically and empirically the socio- managerial and psychologicalpedagogical conditions for the development of future specialists in the field of education readiness to participate in the processes of international student mobility. Research methods: analysis of conceptual positions and a critical review of research on the problem of international student mobility, student questionnaires, methods of descriptive statistics. The results of an empirical study of incentives and inhibitors of future teachers ' participation in the processes of educational and scientific exchange between higher education institutions are presented. Based on the results of the study, the authors provide a justification for the need to develop systematic measures to overcome organizational and managerial, competence-activity, and sociopsychological barriers to international student mobility.
\end{abstract}

\section{Introduction}

Academic mobility of students today is one of the most important components of the higher education system and a means of integrating universities into the modern international educational space. Academic mobility, according to many researchers, cannot be considered only as a set of specific programs, technologies, mechanisms associated with the exchange of students and representatives of the teaching staff of educational institutions of various countries.

As international experts emphasize, in reality, academic mobility contributes to complex and multidirectional processes of scientific and cultural exchange, of the integration of intellectual resources and educational technologies. It also helps to improve the academic, intellectual, social and personal potential of future highly qualified specialists. The academic mobility of students is supported by the governments of different countries. It is also

\footnotetext{
*Corresponding author: olga_gukalenko@mail.ru
} 
implemented in the form of certain international exchange programs based on agreements at the interstate and interuniversity level $[1,2,3]$.

Student mobility is funded from various sources. This is carried out, as a rule, in the form of payment of scholarships, awards for grants allocated by universities, foundations, companies $[4,5,6]$. There are also partial and / or full self-financing mobility programs. Much has been done today to internationalize higher education.

Leaders and staff note that higher education institutions have created a common organizational culture that supports internship and course initiatives. Currently, educational programs of joint training with foreign universities are being implemented in many specialties of the first and second stages of higher education. Internships for teachers and students are organized. Now the possibilities of access to foreign scientific and professional Internet resources have been created.

Nowadays, for example, the traditional ERASMUS + exchange (which includes travel) has been supplemented by virtual mobility, or virtual ERASMUS +. The program is designed so that students from different countries can study together without leaving home [7]. All these are signs of the actively developing external internationalization of higher education, which has a positive effect on the level of professional competence of the future teacher. The objectives of the internship for students in the framework of academic mobility are a deeper formation and consolidation of existing skills and abilities. They receive an incentive to develop new professional competencies.

Academic mobility in the course of a student's higher professional education is designed to become an integral part of his curriculum. It also presupposes the implementation of research in whole or in part on the basis of the institution in which the student is being trained. As for the processes of participation of students of the first and second degrees of higher education in the processes of academic mobility, then, undoubtedly, universities are striving to create organizational conditions for the participation of students in them. However, this raises questions of an internal, psychological plan [8].

\section{Methodology and methods}

\subsection{Methodology}

Research hypothesis. When conducting the research, we proceeded from the idea that the problem of students' readiness for new forms of organization of the educational process, such as academic mobility, is directly related to the phenomenon of the hierarchy of motives. In the hierarchy of motives, there are both motivators that stimulate the development and implementation of this form of educational and professional activity, and demotivators that inhibit the corresponding actions of the student.

In the hierarchy of motives, there are both motivators that stimulate the development and implementation of a given form of educational and professional activity, and demotivators that inhibit the corresponding actions of the student.

The purpose of the study is to identify motives-incentives and inhibitors of students' academic mobility.

Empirical research object and sample A pilot study was conducted in which took part students of Lomonosov Moscow State University, RUDN University (Moscow, Russia), Yanka Kupala State University of Grodno (Belarus). The number of students who took part in the study is 116 students from all universities. They did not have experience of direct participation in academic mobility programs, but showed interest in issues related to international exchange. 


\subsection{Methods}

A complex of theoretical methods and empirical research methods was used. The group of theoretical methods included the method of retrospective analysis, comparative analysis, analogy, generalization, generalization [9]. From the arsenal of empirical methods, survey methods were used in the form of questionnaires. Descriptive statistics were also used. The results were visualized using the program EXCEL [10].

All students participating in the study were given the opportunity to express their views on the incentives and barriers to their personal participation in the processes of international academic mobility. When conducting the survey, questions of an open and closed nature were used.

The research was carried out in two stages, the purpose of each of which will be revealed during the presentation and discussion of the results.

\section{Methodology and methods}

The first stage of the research was devoted to identifying the opinions and assessments of students about the difficulties that "keep" them from participating in the processes of academic mobility.

The data obtained during the survey were distributed according to the decreasing importance of demotivating factors. The results of the survey are presented in Figure 1.

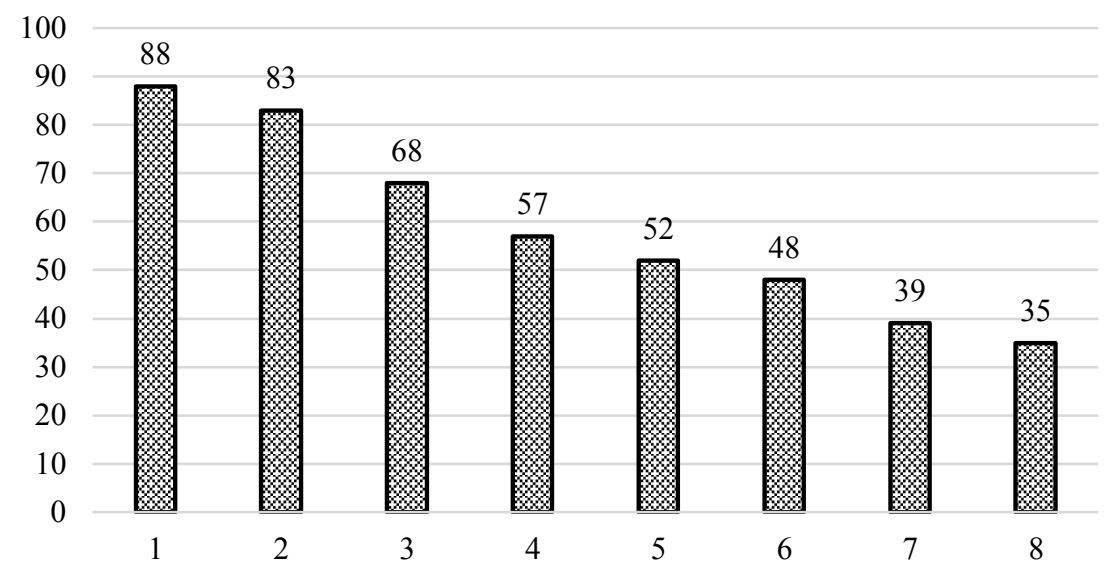

Fig. 1. Students' opinions on the demotivating factors of participation in academic mobility (data are presented as a percentage).

Where: 1 - Insufficient financial provision of mobility; 2 - Insufficient level of foreign language skills; 3 - Education at a high level of difficulty in a foreign university; 4 - - lack of comprehensive information about the conditions, opportunities and limitations within the framework of the mobility program; 5 - Separation and distancing from relatives; 6 - Anxiety about living in another country (culture); 7 - Problems of transferring credits and their accounting in the curriculum; 8 - Separation and distancing from a romantic partner and / or friends.

Analysis of students' opinions about the demotivating factors of student academic mobility allows us to single out organizational and managerial, competence-activity and socio-psychological groups of barriers. The first group is made up of motivations testifying to the lack of knowledge by students of the academic qualifications obtained in various 
countries, about the peculiarities of the organization of educational activities, about the structure of the academic semester, and differences in the curriculum of the specialty.

Among the barriers, the most significant is the lack of confidence of students in their language competence and academic competencies. Knowledge of the language is necessary for a sufficiently effective assimilation of academic disciplines in their specialty in the learning process. This is a condition for "successful" passing of exams and tests in a foreign university. The data obtained in our study are not specific for the students participating in the above survey, but are consistent with the results of studies by foreign authors [11].

In line with the analysis of the problems of academic mobility under the ERASMUS + program, it was found that the majority of respondents indicated a general lack of knowledge of a foreign language as a key constraining factor. Some students were concerned that the study of a foreign language is often not considered by universities as an important component of specialist training. They noted the absence in the curricula of their specialty of a sufficient number of teaching hours for the study of foreign languages.

The survey of students revealed specific, actually social and psychological demotivators of mobility, namely: fears of the emergence of barriers to communication with family and friends, experiencing a sense of social isolation and subjective loneliness in a new environment and environment. Barriers of this kind have been identified and characterized in the study of the processes of self-presentation of students in interpersonal interaction in a new cultural environment [12-15].

The second stage of the study is to identify motivators that encourage students to participate in academic mobility.

It is interesting to consider the positive incentives for academic mobility from the point of view of students who are potential participants (Figure 2).

6

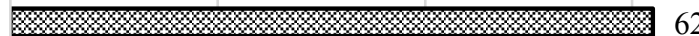

5

\% 69

4
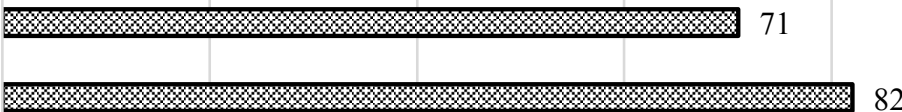

2

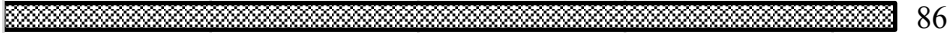

1

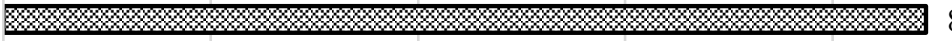

89

0

20

40

60

80

100

Fig. 2 Students' opinions about the factors that induce them to participate in academic mobility (data are presented in percent).

Where: 1 - Improving language competence; 2 - Increasing competence in the field of intercultural interaction; 3 - Improving academic and professional knowledge and skills; 4 Positive experience in overcoming social barriers; 5 - Stimulus to self-education and selfdevelopment; 6 - Prospects for building a career.

Analysis of the motivators that stimulate students to participate in academic mobility gives grounds to assert that, in essence, they reflect the internal motivation of professional and personal self-development and self-improvement. This type of motivation constitutes the meta-level of voluntary self-regulation of the subject of professional activity and life in general. 
The basis of the self-improvement of the subject of activity is the desire of the individual to realize the motives and needs that contribute to the improvement of the activity and personality in order to achieve remote in time, but objectively more valuable goals. The psychological condition, or the driving force of the process of professional and personal selfdevelopment and self-improvement of students, is the emergence of contradictions between the available knowledge and skills, self-assessment of their level of development and the tasks of cognitive or practical activity; between the achieved level of knowledge and new needs for improved knowledge as a prerequisite for a deeper development of a specific area of science and practice.

\section{Conclusion}

Thus, the readiness of students to participate in academic mobility is a complex structural and functional psychological education, due to both external and internal contradictions.

It performs motivating, directing, regulatory, control and other functions. The hierarchy of motives-incentives and motives-inhibitors as an integral system of all motives determines and regulates the process of academic activity of the future teacher.

The more students have a dominant attitude towards self-improvement, continuous professional and personal growth, the more they will show their subjectivity, overcoming barriers of the social and organizational order and make the most of the opportunities of academic mobility to develop their intellectual, competence and cultural potential.

\section{References}

1. S.V. Ryazantsev, S.M. Shakhray, A.A. Yanik, Herald of the Russian academy of sciences 90(1), 15 - 24 (2020)

2. O. Fedotova, Procedia. Social and behavioral sciences 214, 414-421 (2015)

3. E. Platonova, O. Fedotova, J. Bogomolova, $10^{\text {th }}$ International conference of education, research and innovation (ICERI2017) (IATED, Seville, 2017)

4. H. de Wit, International Student Mobility Perspectives: Policy and Practice in Higher Education (2012)

5. V.I. Kazarenkov, T.B. Kazarenkova, $13^{\text {th }}$ Conference of the European Sociological Association (Un) Making Europe: Capitalism, Solidarities, Subjectivities Abstract book (European Sociological Association) (2017)

6. M. Nikunen, K. Lempiainen, Gender and education 32(4), 554-571 (2020)

7. M. Souto-Otero, et al., Educational Researcher 2(42), 71-73 (2013)

8. M. Knobel, M.C. Lima et al., ETD Educacao Tematica Digital 22(3), 672-693 (2020)

9. L. Cohen, L. Manion, K. Morrison, Research methods in education (Routledge, NY, 2007)

10. J. Freeman, S. Walters, M. Campbell, How to display data (Blackwell Publishing, Massachusetts, USA, 2008)

11. O. Fedotova, P. Ermakov, et al., 13th International technology, education and development conference (INTED2019) (IATED, Valencia, 2019)

12. O. Gukalenko, V. Borisenkov, SHS Web of Conferences 9, 01026 (2016) https://www.shs-

conferences.org/articles/shsconf/pdf/2016/07/shsconf_eeia2016_01026.pdf 
13. V.P. Borisenkov, Polycultural educational space of Russia: history, theory, design bases: Monograph (RGPU Publishing House, Moscow, 2004)

14. Z. Erdosova, R. Juarez Toledo, Revista De Educacion Inclusiva 13(1), 104-124 (2020)

15. O. Fedotova, Edulearn proceedings, 45-54 (2012) 